Probably, however, the strongest indication that the ties of kinship are still operative lies in the fact that the community is able to manage at all, for a real abdication by the younger generation from the care of their old people would completely submerge our present resources.

This leads to an urgent problem-that of raising the family to a position of recognized partnership, for the family is indeed the dominant partner in the enterprise. and it is only when relatives are absent, as in the case of the isolate, when they fail, or when the burden is too great for them that the community services become necessary. This has immediate relevance to the stresse: now imposed on the services in hospitals for acute cases. which have already been mentioned. It entails the elevation of early and adequate consultation with the family into a position of prime importance in the management of acute illness in an old person.

\section{A Social Problem}

In old people physical or mental illness is as much a social as a technical problem, and in the future this point of view will need to be recognized as of the greatest importance to the hospital services. Only too irequently, when an old person is admitted for an acute illness, the relatives are not brought up against their responsibilities until a relatively late stage in the illness -usually when discharge home is suggested. This may happen after various domestic changes have been made at home, and then. when the approach to them is made, as it almost invariably is, by someone in a position of secondary authority - the whole set-up is conducive to an atmosphere of rebellion. The response might have been different had they been seen at the outset by someone-such as the doctor in charge, whose authority they accept. The encouraging experience of the more progressive geriatric centres, where the enlistment of the children's support is regarded as a matter of primary importance, shows what can be done. It need hardly be added that in this field the general practitioner plays a part of fundamental importance, and that to a large extent the success of a geriatric unit in hospital hinges on his co-operation in the domestic care of old people. It should be borne in mind that the final illness of an old person may not only be prolonged but also have ups and downs.

It is becoming increasingly recognized in geriatric practice that to obtain the loyal assistance of the family two measures are necessary: (1) the opportunity of an actual interview with the consultant in charge-as early as possible and, at any rate, as soon as a reasonable discussion of the present situation and future developments is possible; and (2) the promise by the hospital of immediate readmission for any urgency, whether technical or domestic-the policy of intermittent readmission. As has been said, it is the experience of geriatric units that when the relatives realize that the hospital regards them as equal partners in a common enterprise and is prepared to help if matters become more difficult, then the relatives will pull their weight. Success in this effort is not only essential to the community but may also be of inestimable benefit to the old person, for, next to the death of a beloved spouse, probably the bitterest blow that life can deal to old people is the realization that their children no longer want them. They then indeed do become outcasts from society-desolates as well as isolates.

\section{Conclusion}

It is important not to forget the assistance that has been given in the past by good neighbours-in 1946 it was esimated that they provided nearly $20 \%$ of the home nursing of old men and $30 \%$ of that of old women. The changes in housing arrangements and in employment tradition have led to the severance of many intangible human ties, and one may, in fact, say that the major problem of the present time is to promote the conditions in which these ties of human affection, whether as kinsmen or as neighbours, can continue to flourish and so support the evening of the lives of our older people.

\section{REFERENCES}

Abel-Smith, B., and Titmuss, R. M. (1956). The Cost of the National Health Service in England and Wales. University Press, Cambridge. (Quoted by Townsend (1957), p. 184.)

Durand, J. D. (1955). In Old Age in the Modern World, p. 33. Livingstone, Edinburgh.

Hornsby-Smith, P. (1956). In The Care of the Elderly, p. 67 Report of 8th Conference of the National Old People's Welfare Council, London.

Report of the Committee of Inquiry into the Cost of the National Health Service, 1956, Cmd. 9663, p. 217. H.M.S.O., London.

Royal Commission on Canada's Economic Prospects (1957). Output, Labour and Capital in the Canadian Economy, p. 176 .

Sheldon, J. H. (1948). The Social Medicine of Old Age. Oxford Univ. Press, London.

Titmuss, R. M. (1955). In Old Age in the Modern World, p. 49. Livingstone, Edinburgh.

Townsend, P. (1957). The Family Life of Old People: An Inquiry in East London. Routledge and Kegan Paul, London.

\section{PROBLEMS OF AN AGEING POPULATION*}

\section{BY}

MARTIN ROTH, M.D., F.R.C.P.

Professor in Psychological Medicine, University of Durham

The problems of ageing of the population are widely recognized as being of fateful significance both in the highly developed countries, whose populations are held by many to be ageing too much and at a too rapid rate, and in the underdeveloped parts of the world, whose populations would probably benefit from reproducing less and growing more aged. But it is in the highly industrialized and relatively affluent parts of the world that medicine is being compelled to an increasing exterit to direct its attention to problems that bear some relationship to the ageing process. Mental illness is one of these problems, for the chance of developing it increases with advancing age. This is clearly evident in the Table and the Figure, which show that there is a steep rise in the first admission rate to mental hospitals between ages. 16 and 25 and thereafter a more steady increase in women, while the rates for men show a temporary decline in the middle years. However, after the age of 65 the curve shows a steep upward gradient for both sexes. The curves for total admissions to mental hospitals are very similar in shape. It is not generally appreciated that it is only in age groups beyond 65 years, even according to the Registrar-General's figures, that the organic psychoses of senescence (mainly recorded under the heading of senile psychosis) become * Paper read to a Plenary Session at the Joint Annual Meeting of the British Medical Association and Canadian Medical Association, Edinburgh, 1959. 
predominant as causes of mental disorder leading to admission to a mental hospital. There is, moreover, some reason to believe that official statistics may underestimate the relative proportion, among the aged, of mental disorders which carry a far better prognosis and are not essentially different from psychosis and neurosis in earlier life (Roth, 1955).

However, the different types of "functional " mental illness differ widely in their age of onset. The great majority of cases of schizophrenia begin between the ages of 15 and 50, and the peak for first admission rates is in the late twenties; between the ages of 20 and 40 , when it takes its most heavy and terrible toll, the male admissions are far in excess of the female. On the other hand, manic-depressive psychosis, which is largely manifest as depressive illness, while a considerable problem already in the third decade, shows a steady rise in first admission rates, to reach a peak at about 65 years, and in most of the age-groups at risk women predominate (Brooke, 1958). Between the ages of 45 and 65 depressive illness is by far the most important single cause of admission to mental hospitals; but it remains common after 65 and is probably important as a cause of mental ill-health among old people in the community. Neuroses resemble schizophrenia in so far as most cases begin between the second and fifth decades (Shepherd and Gruenberg, 1957). Other things equal, a rise in the relative proportion of the aged will therefore tend to increase the total incidence of mental disorder in the population and that of manic-depressive psychosis and the organic disorders of the aged in particular, while schizophrenia and neurosis will be likely to decline in relative importance.

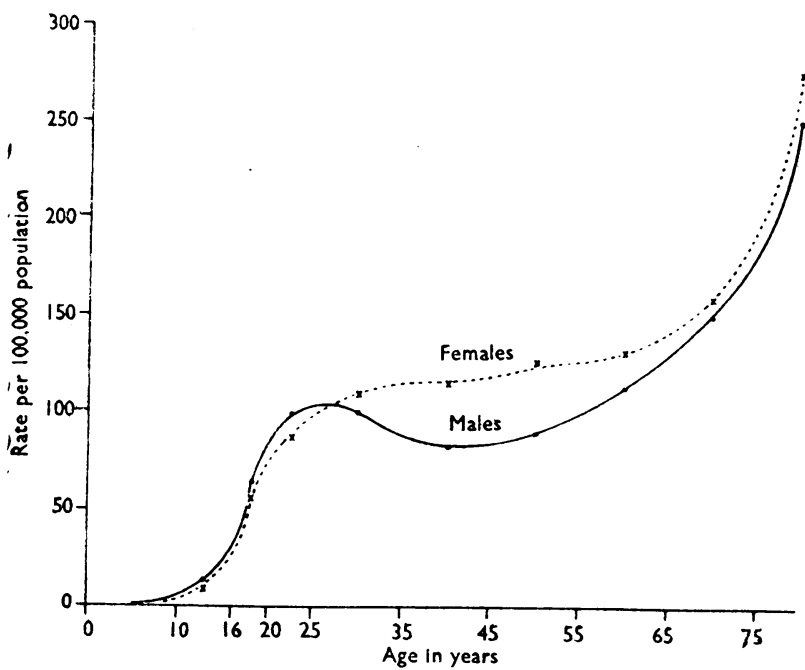

Rates of first admissions to mental hospitals per 100,000 of estimated population, 1951 .
The suicide rate, like that for manic-depressive psychosis, mounts with advancing age ; the peak rate for consummated suicide is to be found in old age or late middle age in nearly every country for which statistical data are available. Moreover, though a general decline in overall rates has occurred in many countries in the past 15 to 25 years, the aged have on the whole benefited relatively little. In England and Wales, for example, the incidence of suicide since the end of the second world war has fallen for all age-groups but least for those over 60 , while the rates for women over 60 have increased and are still rising. The figures for many other European countries tell the same tale (World Health Organization, 1956).

Little is known about the frequency of mental illness among old people outside hospital, since none of the surveys that have been conducted to investigate their health was specifically designed to yield such information. But only a proportion of those mentally ill at a given time are to be found in mental hospitals or psychiatric clinics. In Great Britain there are probably over 60,000 cases of senile psychosis alone-the most grave and disabling form of mental illness in old ageand this constitutes only a fraction of the mental health problem. In those surveys which make some mention of the mental health of the aged, apathy, depression, fear, and hopelessness are mentioned in a proportion which ranges from 11 to $50 \%$.

\section{The Aged and the Community}

The view of physicians, psychiatrists, and social and welfare workers tends to be confined to the black side of the picture. We tend to think in terms of lonely old people and selfish, irresponsible children, forgetting that $95 \%$ of the aged are living outside institutions. Moreover, investigations have provided ample evidence that the bonds within most families are strong and enduring, and that the aged remain an integral and often vital part of the family unit, living near and usually in regular contact with one or more of their relations (Townsend, 1957). However, even if as many as two-thirds lead lives that are full, happy, and secure, there remain about one-third, composed of the isolated and inactive, the infirm, and the sick. And there is a marginal group constituting some 10 to $15 \%$ of the total that survive in the community with difficulty or at the cost of great hardship to children or relations who are nowadays rarely capable of sustaining such burdens without aid. The crucial point is that even less than $5 \%$ of old people in institutions and special homes are pressing heavily upon the health and welfare services and in some places are in danger of causing them to burst at the seams.

There is little doubt that if for some reason the adjustment of a substantial proportion of the marginal

Age Distribution of First Admissions to Mental Hospitals in 1951

\begin{tabular}{|c|c|c|c|c|c|c|c|c|c|c|c|c|}
\hline & \multirow{2}{*}{ Sex } & \multicolumn{10}{|c|}{ Age-groups } & \multirow{2}{*}{ All Ages } \\
\hline & & 0 - & 10 & 16 & 20 & $25-$ & 35 & 45 & $55-$ & 65 & $75+$ & \\
\hline Numbers $\ldots \quad \ldots\{$ & $\underset{\mathrm{F}}{\mathrm{M}}$ & $\begin{array}{l}47 \\
22\end{array}$ & $\begin{array}{l}213 \\
149\end{array}$ & $\begin{array}{l}535 \\
614\end{array}$ & $\begin{array}{l}1,224 \\
1,281\end{array}$ & $\begin{array}{l}3,025 \\
3,515\end{array}$ & $\begin{array}{l}2,695 \\
3,914\end{array}$ & $\begin{array}{l}2,567 \\
3,937\end{array}$ & $\begin{array}{l}2,308 \\
3,368\end{array}$ & $\begin{array}{l}1,514 \\
2,658\end{array}$ & $\begin{array}{l}2,065 \\
3,038\end{array}$ & $\begin{array}{l}16,193 \\
22,496\end{array}$ \\
\hline $\begin{array}{l}\text { Proportion per } 1,000 \\
\text { total admissions }\end{array}$ & $\stackrel{\mathrm{M}}{\mathrm{F}}$ & $\begin{array}{l}887 \\
733\end{array}$ & $\begin{array}{l}842 \\
819\end{array}$ & $\begin{array}{l}752 \\
757\end{array}$ & $\begin{array}{l}645 \\
685\end{array}$ & $\begin{array}{l}587 \\
636\end{array}$ & $\begin{array}{l}619 \\
602\end{array}$ & $\begin{array}{l}648 \\
589\end{array}$ & $\begin{array}{l}659 \\
597\end{array}$ & $\begin{array}{l}737 \\
663\end{array}$ & $\begin{array}{l}880 \\
873\end{array}$ & $\begin{array}{l}663 \\
645\end{array}$ \\
\hline $\begin{array}{l}\text { Rate per } 100,000 \\
\text { civilian population }\{\end{array}$ & $\underset{\mathrm{F}}{\mathrm{M}}$ & 1 & $\begin{array}{r}12 \\
9\end{array}$ & $\begin{array}{l}64 \\
56\end{array}$ & $\begin{array}{l}99 \\
87\end{array}$ & $\begin{array}{r}99 \\
110\end{array}$ & $\begin{array}{r}82 \\
115\end{array}$ & $\begin{array}{r}89 \\
126\end{array}$ & $\begin{array}{l}113 \\
132\end{array}$ & $\begin{array}{l}151 \\
161\end{array}$ & $\begin{array}{l}251 \\
277\end{array}$ & $\begin{array}{l}79 \\
99\end{array}$ \\
\hline
\end{tabular}

Permission has been obtained from the Controller of H.M. Stationery Office to reproduce the Table and Figure from the Registrar-General's Statistica Review of England and Wales, 1950-51, Supplement on General Morbidity, Cancer and Mental Health. 
group of infirm and mentally impaired aged were undermined, the health and welfare services would be faced with an impossible task and might be overwhelmed.

The psychological attitude of the community to a problem of this dimension is supremely important. It is not only old people who are dependent, but also very young children. That there is a greater psychological resistance to accepting communal responsibility for old, as opposed to young, denendants is suggested by the fact that reference is rarely made to the valuable but imponderable contributions of the aged in caring for grandchildren, transmitting knowledge about chilirearing and household crafts, and influencing human relationships with their wisdom and experience. It is well to re-emphasize that talk about "medicated survival" is ill-informed and un'cloful. The main factor underlying the ageing of populations is not greater expectation of life so much as a decline in fertility, which began in Western Europe, for example, at the beginning of this century. This is an integral constituent of the advance in living standards. An arrest in population growth, whose desirable consequences we now enjoy, has as its inevitable concomitant ageing of the population. We cannot have our cake and eat it.

\section{Ageing and Health in Early Life}

I should like briefly to consider the means at our disposal for relieving the burden which mental illness among the aged lays everywhere on the health and welfare services. It is probably the largest single constituent of the problem of senescence. To some extent we are no doubt dealing with biological factors of which our understanding at present is rudimentary and which can be influenced only within narrow limits. The post-reproductive phase of life may be regarded as a backwater of the evolutionary process which is beyond the reach of natural selection, for this operates only so long as genes produce some impairment of fertility (Medawar, 1957). More specifically, there is evidence to indicate that hereditary factors are partly responsible for suc') conditions as the senile dementias (Sjögren, Sjögren, and Lindgren, 1952) and even functional psychoses such as the depressions and paranoid illnesses of the aged (Kay, 1959). But these hereditary factors need not frighten us into inactivity. In so far as they have been shown to operate in relation to ageing and its caricature in senile psychosis, these genetic factors would appear to be similar in character to those that decide variation in graded characteristics such as stature and intelligence. Environmental influences always contribute to variation in attributes of this nature.

Moreover, there is a very wide range of variation in the extent to which faculties decline and to which old age is burdened with mental illness among individuals and social groups in different environmental settings. The striking differences in the rate at which the signs of ageing appear in underdeveloped and in highly developed conntries-as demonstrated, for example, by the work of Gillman and Gillman, (1951) for South Africansthe increased hazard of admission to mental hospitals in old age among the poor and underprivileged and among the inhabitants of areas of social disorganization and high mobility (Faris and Dunham, 1939 ; Rose and Stub, 1956), present an immediate challenge. Detailed analysis and investigation of such differences might suggest measures that could within the foreseeable future influence deficiencies that we are accustomed to atiribute to "age:ng."
The analysis of such facts has not proceeded very far. But it seems likely that many of the deficiencies and diseases which we encounter among the aged are the culmination of changes over many years or perhaps during the whole of the life-span. Genetic factors apart. the acquisitions of early life, whether intellectual. emotional, or nutritional, are the main sources of vitality in old age. If we want to intervene effectively we therefore have to take action long before senescence This is the lesson that emerges from every field of investigation of the problems of the aged, wheiher concerned with their health, adjustment, employment housing, or the use of their leisure. We do not know how to avoid specific menial diseases of the aged, nor the decline in ingenuity and capacity for abstract thought, and the increased forgetfulness and inflexib:lity it brings in varying degrees. But something is almost certainly contributed to healthy ageing by fostering personal adjustment and fulfilment and physical and mental well-being at earlier stages of development.

In medicine we have yet to adapt our vision to the change in expectation of life in the last half-century. Our thinking about the prognosis of illness or the effects of treatment is narrowly focused upon the few years that follow. The time has long since arrived when we should be asking ourselves how this man of 40 will fare with his neurosis or duodenal ulcer or without his frontal lobes or his stomach at 65 . We shall have, in fact, to cultivate the habit of asking the question, "What is this neurotic and eccentric or bronchitic and hypertensive person of 40 going to be like at 70 , and what can te done to protect him against the possibility of an old age darkened by loneliness and depression and mental or physical infirmity?"

The effects of our actions are enduring ever long 2 r as living testimony to our imagination or lack of foresight, and the time has arrived when we should be takir. a long-term view. The enrichment of assets should go hand in hand with the anticipation of deficiencies. So far as assets are concerned, it is noteworthy that the individual of outstanding intellectual or creative ability seems often able to continue his work into old age and will then sometimes register his finest achieven ent. But the early start is characteristic and perhass essential. There should therefore be ample outlets for creative gifts before the forties, when they arc already in decline. The present tendency in our culture to postpone the assumption of high responsibility to a progressively later stage in life in an ever-widening range of careers seems to be seriously at variance with our knowledge of the evolution of mental attributes. So far as deficiencies are concerned, Dr. Heron (1958) put it in a nutshell in discussing the problem of adaptation to the changing demands of working life. "We must act," he said, "in such a way that instead of wondering what to do with old Bill when he is past it and has become a problem, we shall have averted the problem by anticipating it 15 or 20 years earlier.'

\section{Social Aspects}

The social aspects of the problem of mental disorder in old age are important and also remediablepotentially at any rate. Loneliness is a vast problem in modern civilization ; for example, 1,400,000 people were living alone in this country in 1951 as compared with less than half this number in 1931 (General Register Office, 1952). It is a problem that leans especially heavily on the aged. Isolation, together with physical 
illness, fear of losing independence, and diminished income, is a characteristic setting for mental disturbance and suicidal attempts. Some of our difficulties in this connexion are unavoidable. Increased social and geographical mobility is an integral part of modern social development, and when the young and adventurous leave their home town in search of opportunity the aged may be left without anyone to care for them in sickness. Yet our assets in this respect are greater than generally estimated. As Townsend and others have shown, the three-generation family continues to thrive in the middle of many great cities and exhibits a natural strength which is surprising to those who habitually bemoan the waning of filial piety.

But we squander our resources; many of the new suburban residential areas and satellite towns are at present communities of the young. Twenty-five to thirty years hence they will be communities of the middleaged and elderly alone. This sort of community development often takes place with haphazard regard for the wishes and emotional needs of both the young and the older generation (Young and Willmott, 1957).

The feeling of not belonging, of having no acceptable contribution to make, that many old people experience in many countries of the world to-day, owes something to the value that has come to be placed, for obvious historical reasons, on the "frontier" attributes of initiative and disregard for precedent which are associated in the popular mind with youth. A disproportionately high value is perhaps placed on youthfulness, and ageing and death appear to be rapidly replacing sex as the major taboos in our society. Whatever the blessings of youth, the social attitudes which are developing show a lack of maturity and balance and have much that is akin to the neurotic treatment of emotional problems, as witness the repellent euphemisms often used to describe the aged and dead. It is hardly necessary to mention that this is not the first time in history that attitudes to ageing and death have been unhealthy. In the Middle Ages many old people with recognizable mental disorder were tried as witches, and there is a particularly vivid description of psychotic self-accusation and abasement in North's (1887) account of the Exeter trial. "The evidence against them was very full but their own confessions exceeded it. They appeared not only weary of their lives but to have a great deal of skill to convict themselves." This was also the age of the sickly, morbid phantasmagorias of Hieronymus Bosch.

In the eighteenth century, on the other hand, more natural and robust attitudes prevailed in some countries, as characteristically reflected in the following conversation.

Boswell: "What I admire in Ramsay is his continuing to be so young."

Johnson: "Why yes sir, it is to be admired. I value myself upon this, that there is nothing of the old man in my conversation. I am now sixty-eight and I have no more of it than at twenty-eight."

Boswell : "But sir, would you not wish to know old age? $\mathrm{He}$ who is never an old man does not know the whole of human life ; for old age is one of the divisions of it."

Johnson: "Nay sir, what talk is this?"

Bosweil: "I mean sir, the sphinx's description of it; morning, noon and night. I would know night as well as morning and noon."

Johnson: "What, sir, would you know what it is to feel the evils of old age? Would you have the gout? Would you have decrepitude?"
Seeing him heated-I would not argue any further, but I was confident I was in the right.

Johnson was obsessed by a fear of eternal damnation, yet even his repugnance for growing old is expressed with a vigour and frankness that one finds refreshing nowadays. And we are perhaps prone to hear more of the advantages of being a "senior citizen "than of knowing the whole of human life, decrepitude and all.

\section{Senescence and Disease}

In psychiatry, as in medicine, there has been a growing appreciation during the past few decades that much that formerly passed for the effects of innate decline in senescence is the consequence of specific and often reversible disease. Many old people when afflicted with mental illness become apathetic, inert, retarded, gloomy-and their personal standards may decline so as to suggest advancing senile decay. Extreme agitation or muteness may augment the outward appearance of decrepitude. Yet many patients, presenting thus, suffer. in fact, from a depressive illness which treatment will mitigate or cure. Old people with paranoid psychoses causing excited behaviour, hallucinations, hostility, and vituperative speech may again be improved nowadays by treatment and at times rehabilitated into the community. There is also much to suggest that the alleged immunity of the aged from neurotic breakdown is partly illusory, and that neuroses starting de novo in late life and often mitigated by simple measures are not as rare as hitherto supposed. Fulminating delirious states may render the patient inaccessible, and he may appear in hospital in a moribund state. A relatively short history of illness should lead one to suspect that here, too, the impression of advancing senile degeneration is likely to be erroneous. Underlying such delirious or "confusional" states there is, in a high proportion of instances, a specific physical disease which may be susceptible to treatmeint.

Some of these physical illnesses may produce few of the traditional clinical signs-for example, the "silent" pneumonias and "silent" myocardial infarctions of the aged. The physical illness contributes to the disability and is to some extent important as a cause in all mental disorders of old age - a fact which makes it essential to establish geriatric centres where both full psychiatric and medical facilities are provided. In those in whom a mental illness such as a depression or neurosis is manifest for the first time in senescence, the disability has, in a sense, pursued the most favourable course possible, its manifestation having been postponed until the most active stages of the life-span have been left behind. And there is evidence to suggest, as one might expect, that in the functional psychoses and neuroses of old age genetic loading is relatively smaller and exogenous factors, such as physical illness, bereavement, and isolation, relatively more important in causation than in comparable illnesses in earlier life (Roth and Kay, 1956 ; Kay, 1959).

\section{Some Practical Measures}

We have no specific remedies at present for the main causes of chronicity among the aged in mental hospitals - the senile and arteriosclerotic psychoses, the schizophrenias-who spend their lives there. But a great deal could be done to ease the burden upon psychiatric institutions if remediable disorders were identified and treated at their earliest stages and the facilities for skilled 
and energetic rehabilitation into the community everywhere established. One of the most serious problems is that the majority of cases of mental ill-health come under observation only after some crisis, whether social or medical, has arisen. The illness is then often welladvanced (Post, 1959), the family perhaps demoralized, and the situation as a whole irremediable. A great deal more could be achieved if our facilities for detecting those who are isolated, immobile, in grief, or in need for other reasons, could be improved.

This underlines once again the need to deal with the problems of ageing well before they force themselves upon our attention. Effort invested early in life in fostering interests, in helping the individual to cultivate friendships and social activities, would yield some dividend. Tolerance and flexibility in personal relations cannot be cultivated in old age and it is too late then to begin the quest for fulfilment. The problem of inactivity and unused resources is at its most acute for old people, but it will soon be a much greater problem for society as a whole. We are on the threshold of an age of automation in which unprecedented amounts of leisure will become available not only for those over 65 but for persons of all ages. Education has yet to be geared to a world in which the over-fifties will equal the under-twenties and in which the leisure and the opportunity this creates will be available to an extent undreamt of even a short while ago.

Our means for attacking some of the problems of mental health in the aged are by no means negligible. We need to intensify scientific inquiry into the wide variation in the extent to which faculties decline and to which old age is burdened with illness among individuals in the same and different social groups. All disciplines have a part to play in this quest: genetic, physiological, epidemiological, sociological, and psychiatric. Meanwhile a great deal could be achieved through a better utilization of existing knowledge of the medical and social aspects of mental health in old age; the promotion of physical well-being in early life ; the application of greater imagination to, and the consultation of, the human beings affected by community development; the attack on loneliness and isolation; and the early discovery, diagnosis, and treatment of physical and mental illness among the aged, with recognition of the early signs, particularly of depressive illness and suicidal risk. Those who have made suicidal attempts, so often determined and successful among the aged, could be given more adequate rehabilitation and after-care. I shall not add to the volume of words spoken on the need for integrating the different agencies involved in the care of the aged beyond saying that we are not likely to progress far beyond pious platitudes until a sincere attempt is made by all the persons concerned to place the needs of the aged individual far above all administrative consideration.

The importance of such a many-sided attack upon the problem has been shown by some observations in Sweden on changes in the incidence of invalidism during the past few decades. In an ageing population one would expect the rate to show a steep rise. In fact, the incidence of invalidism in Sweden has fallen in the past 25 years (Sjögren and Larsson, 1960), showing that advances in medicine and the social services may more than offset some of the adverse effects arising from ageing of the population. We have a very long way to go before we can claim to have exploited all the resources at our disposal for offsetting these effects, and can blame ignorance of the nature of "ageing" as the principal cause of our inability to reduce further the ill-health and unhappiness of many old people.

\section{Summary}

An increase in the total incidence of mental disorder, and of affective psychosis and the organic psychoses of the aged in particular, may be one of the consequences of ageing of the population. Although less than $5 \%$ of people over 65 are in institutions and special homes, the health and welfare services in many areas are already showing signs of strain. Some possible approaches to the problem are discussed. The foundations of physical and mental well-being in old age-so far as they can be influenced-are laid in the early and middle years. Fostering health, adjustment, interests, and outlets well in advance of old age, mitigating loneliness and desolation, helping where possible to conserve family ties, and imaginative planning and community development with an eye to human needs-all have something to contribute. The long-term effects of diseases and major surgical procedures upon the pattern of ageing need to be considered and investigated. Effective remedies are now at our disposal for some mental disorders formerly attributed to "ageing," but their full utilization is impeded by the difficulties of locating depressed, sick, and infirm old people at an early stage of illness. The association between physical and mental health is particularly close in senescence; and integration of psychiatric and medical services, as also of the various agencies concerned in providing them in hospital and in the community, is essential. The expected rise in invalidism consequent upon ageing of the population may be offset for some time ahead by medical and social progress.

This paper owes much to the Sixth Report of the Expert Committee on Mental Health of the World Health Organization on "Mental Health Problems of Aging and the Aged" (to which I acted as a consultant on behalf of W.H.O.) and to the working paper prepared by me for the Committee.

REFERENCES

Brooke, E. M. (1958). Monthly Bull. Minist. Hlth Lab. Serv. 17, 208.

Faris, R. E., and Dunham, H. W. (1939). Mental Disorders in Urban Areas. University of Chicago Press, Chicago.

General Register Office (1952). Census 1951. Great Britain. One per cent. Samples: Part I. H.M.S.O., London.

Gillman, J., and Gillman, T. (1951). Perspectives in Human Malnutrition. Grune and Stratton, New York.

Heron, A. (1958). Address to Industrial Efficiency and Productivity Exhibition, Manchester, November, 1958

Kay, D. W. K. (1959). Proc. roy. Soc. Med., 52, No. 9, 791.

Medawar, P. B. (1957). The Uniqueness of the Individual pp. 17-43. Methuen, London.

North, R. (1887). Autobiography, edited by A. Jessopp. London.

Post, F. (1959). Geront. Clin., 1, 114.

Rose, A. M., and Stub, H.'R. (1956). In Mental Health and Mental Disorder, p. 87. Routledge and Kegan Paul, London. Roth, M. (1955). J. ment. Sci., 101, 281 .

Roth, M. (1955). J. ment. Sci., 101, 281. (1959). Bull. Wld Hlth Org., 21, 527.

Shepherd, M., and Gruenberg, E. M. (1957). Milbank Mem. Fd Quart., 35, 258.

Sjögren, T., and Larsson, T. (1960). Working paper given to expert committee on mental health, September, 1958. Geneva. In press.

Sjögren, H., and Lindgren, A. G. H. (1952). Acta psychiat. scand., in Suppl. 82

Townsend, P. (1957). The Family Life of Old People: An Enquiry in East London. Routledge and Kegan Paul, London.

World Health Organization (1956). Epidem. vital statist. Rep.,

9, 258. (1959). Mental Health Problems of Aging and the Aged Sixth Report of the Expert Committee on Mental Health. Technical Report Series, No. 171. Geneva.

Young, M., and Willmott, P. (1957). Family and Kinship in East London. Routledge and Kegan Paul, London. 